\title{
Astaxanthin from crayfish (Procambarus clarkii) as a pigmentary ingredient in the feed of laying hens
}

\author{
By A. Pérez-Gálvez ${ }^{1}$, J. J. Negro-Balmaseda², M. I. Mínguez-Mosquera', \\ M. V. Cascajo-Almenara ${ }^{3}$ and J. Garrido-Fernández ${ }^{* 1}$
}

\author{
${ }^{1}$ Grupo de Química y Bioquímica de Pigmentos. Departamento de Biotecnología de Alimentos, \\ Instituto de la Grasa (CSIC). Av. Padre García Tejero 4, 41012, Sevilla, Spain. \\ ${ }^{2}$ Unidad de Biología Aplicada, Estación Biológica Doñana (CSIC). Apdo. 1056, 41080, Sevilla, Spain. \\ ${ }^{3}$ Departamento de Fisiología, Anatomía y Biología Celular. Centro Andaluz de Biología del Desarrollo. \\ Universidad Pablo de Olavide. Ctra. de Utrera, Km. 1, 41013, Sevilla, Spain. \\ Corresponding author: jgarrido@ cica.es
}

\section{RESUMEN}

Astaxanteno procedente de cangrejo (Procambarus clarkii) como ingrediente colorante en la alimentación de gallinas ponedoras.

La yema de huevo de gallina debe su coloración a la presencia de carotenoides de tonalidad amarilla. La adición de colorantes sintéticos de tonalidades rojas permite modificar e incrementar la coloración de la yema desde el amarillo original a tonos rojos que pueden ser demandados en ciertos mercados según las preferencias del consumidor. El objetivo del trabajo fue probar si un triturado obtenido a partir de caparazones de cangrejo, que es una fuente natural y rica en astaxanteno, produce cambios detectables en la coloración de la yema de huevo por la acumulación de dicho carotenoide. Las gallinas ponedoras se alimentaron con un pienso comercial al que se adicionó triturado de caparazón de cangrejo. Se realizó un seguimiento de los cambios en la composición carotenoide (mediante HPLC) de la yema de los huevos puestos durante el periodo de alimentación suplementada. Los análisis mostraron una progresiva incorporación de astaxanteno que alcanzó niveles similares al resto de carotenoides presentes inicialmente en la yema.

PALABRAS-CLAVE: Astaxanteno-Carotenoides - Cangrejo - Color - Yema de huevo.

\section{SUMMARY}

Astaxanthin from Crayfish (Procambarus clarkii) as a Pigmentary Ingredient in the Feed of Laying Hens.

Chicken egg yolks generally owe their color to yellow carotenoids. The addition of synthetic red pigments allows changes in color, from the original yellow to red hues which may be more appealing to consumers in certain markets. Our aim has been to test whether ground crayfish shells, which are a rich and natural source of astaxanthin, produce detectable changes in the coloration of egg yolks through the accumulation of this carotenoid. Laying hens were fed with a commercial feed mixed with crayfish powder and the carotenoid profiles of the yolks in the eggs laid during the trial were monitored by HPLC. The analyses showed a progressive increase in the astaxanthin concentration in the egg yolks, reaching similar levels to those obtained for the rest of present carotenoid pigments.

KEY-WORDS: Astaxanthin - Carotenoids - Color Crayfish - Egg yolk.

\section{INTRODUCTION}

Although the biosynthesis of carotenoids can only be carried out by plants, algae and bacteria, this kind of natural pigments is also found in animals, mainly mammals, fish and birds that incorporate carotenoids through their diet (Goodwin, 1984). Carotenoids in birds are not limited to feathers but also the skin of various exposed parts such as legs, feet, bill, and comb may contain carotenoids. They play an important role as coloring elements and, in the case of birds, they are a discriminatory factor for males and females (Bortolotti et al., 1996; Negro et al., 2000). As aforementioned, diet is the main factor in the kind and amount of carotenoids incorporated which are also distributed to internal organs and lipophilic tissues or fatty aggregates like egg yolks. Carotenoids act as antioxidants and control several factors in the formation and cell differentiation of embryons (Royle et al., 1999).

The color of egg yolk plays an important role in the egg production industry and is a direct consequence of the type and amount of carotenoids present, which come from diet. So the bioavailability of carotenoids must be considered together with factors that modify it, mainly the kind of carotenoid and the matrix where they are initially present (Karunajeewa et al., 1984). Preferential absorption in the yolk of lutein and zeaxanthin is achieved, while $\beta$-carotene and others without functional groups such as hydroxyl or keto groups are poorly incorporated (Marusich and Bauernfiend, 1981).

The commercial trade of eggs is based on different qualities with the color of yolk as the main factor. Depending on its final use (table eggs or for the food processing industry) the color requirements will be different and producers must be able to change this attribute in function of market demands (Delgado-Vargas et al., 1998; Nys, 2000). The evaluation of yolk color is performed with Roche Yolk Color Fan that includes 15 different tones from light cream-yellow to red (Nys, 2000). 
The first tones are reached with yellow carotenoids but when intense yolk pigmentation is desired (values from 10 to 15 e.g. to produce breaker eggs) pure oxycarotenoids in a dry stabilized form are used, including $\beta$-apo-8'-carotenal, $\beta$-apo-8'carotenoic acid ethyl ester, canthaxanthin and citranaxanthin (Marusich and Bauernfiend, 1981).

The use of synthetic carotenoids avoids major problems in the use of natural ingredients for pigmentation with the advantage that minimal amounts are required to obtain the desired effect. However, these compounds are expensive and new trends for using natural carotenoids as coloring additives are now becoming prevalent (Carranco et al., 2003; Santos-Bocanegra et al., 2004). So, natural feed ingredient sources of carotenoids should be incorporated into the diet to provide a pigmentation source. In the past, yellow corn, corn gluten meal and dehydrated alfalfa meal have been extensively used. In addition, some special concentrates like alga and marigold meals, alfalfa, paprika, annatto and tomato products have been used to augment the carotenoid concentration of these sources (Marusich and Bauernfiend, 1981; Hamilton et al., 1990; Blanch, 1999).

Crustacean products like a shrimp meal were used as a complementary source of pigment. Crustaceans (shrimp, crabs, crayfish and lobsters) contain high concentrations of a red carotenoid, astaxanthin with similar coloring characteristics as canthaxanthin (Meyers 1981; Chen and Meyers, $1982 ; 1984)$. Previous results support the findings that hens can accumulate astaxanthin in the yolk (Nelson and Baptist, 1968). The red American crayfish (Procambarus clarkii) contains a high concentration of this red carotenoid. Factories that process this animal for human consumption produce waste products that could be used as a supplementary feed pigment in the diet of laying hens.

The aim of this work was to include crayfish powder obtained from plant processing wastes in the diet of laying hens as a complementary source of pigment in order to confirm its effect on yolk pigmentation. Color levels at red marks of Roche Yolk Color Fan could be obtained if astaxanthin is incorporated into the egg yolk together with the normal carotenoid pattern supplied with diet.

\section{MATERIALS AND METHODS}

\subsection{Raw Materials and Animals}

Sixteen Hy-line laying hens (Gallus domesticus) were supplied by Agropecuaria y Avícola S.A. (Sevilla, Spain) as well as individual lock ups and food to feed them during the experiment. The crayfish powder was processed by Ecodryer S.A. (Los Palacios y Villafranca, Sevilla, Spain). This powder is produced by the application of a dehydration process (5-8 seconds, $\left.350{ }^{\circ} \mathrm{C}\right)$ at low pressure. These conditions are applied to crayfish residues with an initial content of $70-80 \%$ moisture and after processing the moisture content is $8-10 \%$. The carbohydrate, fat and protein contents of the crayfish powder are $20.3 \%, 3.3 \%$ and $30.2 \%$, respectively, while the fiber proportion is $12.7 \%$. During $5 \mathrm{~d}$ the normal diet was maintained (milled corn seeds) containing lutein (7.45 $\mathrm{mg} / \mathrm{kg})$, zeaxanthin $(7.86 \mathrm{mg} / \mathrm{kg})$ and canthaxanthin $(2.30$ $\mathrm{mg} / \mathrm{kg}$ ). Then $20 \%$ crayfish powder (provided by Seafood Sevilla S.L.) was added to it, continuing with this diet for $25 \mathrm{~d}$. Hens eat around $100 \mathrm{~g}$ per day of this mixture which was freshly prepared each day $(1600 \mathrm{~g}$ of normal food plus $400 \mathrm{~g}$ of crayfish powder). Before starting the experiment the animals were allowed to have an adaptation period of four days to their new location. The pigment concentration value in the egg yolks corresponding to the fifth day was taken as the reference value (sample 0) and then the diet containing the crayfish powder was established. Eggs taken thereafter correspond to samples 1, 2, 3, etc.

The procedures involving animals were applied following the Directive 86/609/EEC on the protection of animals used for experimental and other scientific purposes.

\subsection{Pigment Extraction}

\section{Crayfish Powder}

The carotenoid profile of crayfish powder consists only of astaxanthin and its concentration was evaluated by spectrophotometrical measurement. Around $200 \mathrm{mg}$ of sample were mixed with acetone. This mixture was sonicated $30 \mathrm{~s}$ and kept in the dark for $30 \mathrm{~min}$. After that time the sample was filtrated and the solvent evaporated in a rotatory evaporator until dry. An appropriate known amount of hexane was added and the astaxanthin concentration determined recording the absorbance value at $470 \mathrm{~nm}$ and using the corresponding extinction coefficient. The astaxanthin concentration in the crayfish powder was $90.3 \mathrm{mg} / \mathrm{kg}$.

\section{Egg Yolk}

A methodology described previously, Surai and Speake (1998), was used but employing acetone as extraction solvent. One gram of egg yolk was extracted with $3.5 \mathrm{~mL}$ of solvent, vortexed for $1 \mathrm{~min}$ and sonicated for $1 \mathrm{~min}$. The sample was centrifuged (9000 rpm during $6 \mathrm{~min}$ ) collecting the upper phase, which was subsequently analyzed by HPLC.

\subsection{Pigment Analysis by HPLC}

HPLC was the technique selected to achieve the separation and quantification of the carotenoid profile present in the egg yolk and poultry feed extracts. The eluent consits of a binary gradient 
of the mixture methanol:acetonitrile:2-propanol (49:49:2) and water. Conditions are detailed in Table 1. Detection was set at $450 \mathrm{~nm}$. Chromatographic separation was developed in a $\mathrm{C}_{18}$ Spherisorb ODS $(250 \mathrm{~mm} \times 4 \mathrm{~mm}$ i.d.) with a guard column of the same material. Quantification of the sample was made using external standard technique (MínguezMosquera, 1997).

\subsection{Measurement of external color of egg yolk}

The hue of the egg yolk was measured by means of the Roche Yolk Color Fan which ranks hues from 1 (light yellow) to 15 (orange).

\subsection{Statistical Analysis}

Values in the text are means \pm SEM. Repeated measures ANOVA analysis was used to compute the significance test $(P<0.05)$. Data were analyzed using STATISTICA statistical software package (STATISTICA for Windows, 5.5; Statsoft, Inc. 1999; Tulsa OK, USA).

\section{RESULTS AND DISCUSSION}

During the experiment the animals did not show any modification in feed and laying habits, and no differences where observed on the weight and consistence of the eggs laid, just on yolk color. Figure 1 shows two chromatograms corresponding to the analysis of egg yolk carotenoid content at the beginning $(A)$ and after 7 days $(B)$ of feeding the hens with the supplementary diet. The carotenoid profile in both analyses reproduces the carotenoid pattern of the diet supplied, with a very simple pigment composition. Chromatogram A shows that lutein and zeaxanthin are the main carotenoids, due to their prevailing presence in the composition of the maize. The chromatogram also shows the presence of canthaxanthin. This carotenoid is intentionally added to the feed in order to increase the color of the egg yolk to the values desired by the producer. Chromatogram B shows that a new peak appears corresponding to astaxanthin, the pigment that colors the crayfish powder included in the feed. It is clear that this carotenoid is accumulated in the yolk.

Table 1

Chromatographic conditions used in the analysis of egg yolk

\begin{tabular}{crcc}
\hline Time $(\boldsymbol{m i n})$ & $\% \mathbf{A}$ & \%B & Curve \\
\hline 0 & 98 & 2 & \\
3 & 98 & 2 & \\
10 & 100 & 0 & 6 \\
15 & 100 & 0 & \\
20 & 98 & 2 & 6 \\
\hline
\end{tabular}
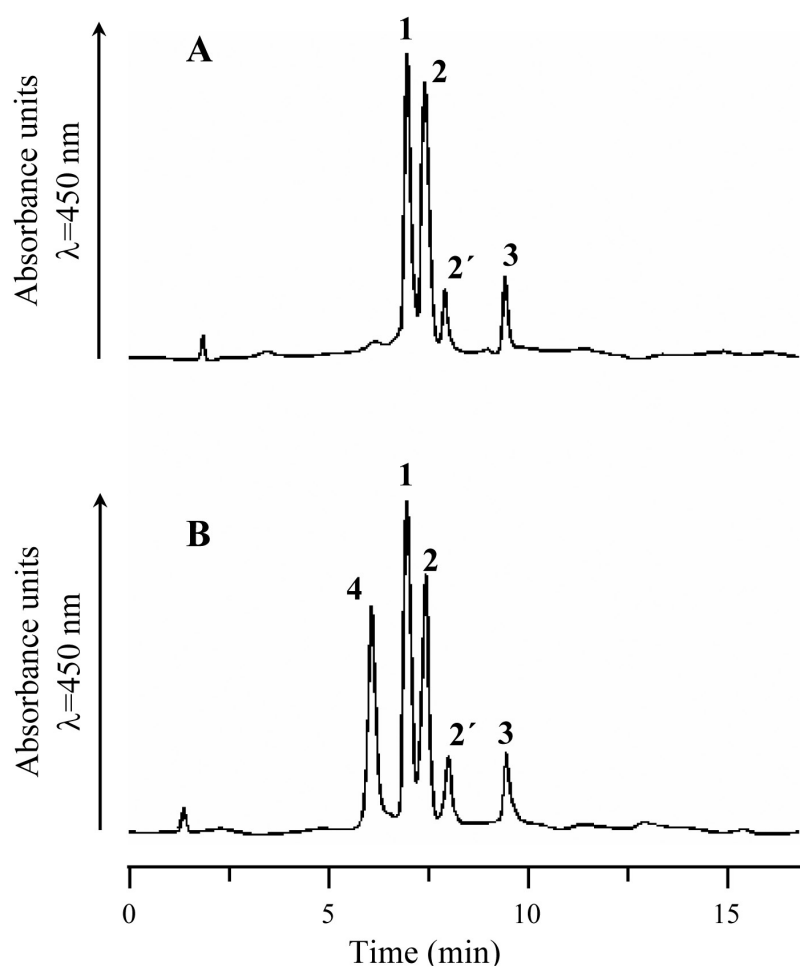

Figure 1

Chromatograms corresponding to the analyses of two egg yolk extracts at the beginning of the study $(A)$ and after 7 days

(B) of including a $20 \%$ crayfish powder in the diet of the hens. Peak identification is as follows: 1, lutein; 2 , zeaxanthin; 2 ', cis-zeaxanthin; 3 , canthaxanthin; 4 , astaxanthin.

Table 2 shows the individual pigment content corresponding to one of the hens (number 5). Sample 1 (the first egg laid after introducing the crayfish powder in the feeding) did not contain any astaxanthin. However, in sample 2 a low amount of astaxanthin was detected. The amount of this pigment increased continuously with time reaching a maximum value after 9-10 days (ca. $21 \mathrm{mg} / \mathrm{kg}$ ) which was maintained throughout the following days. This fact indicates that a balance was reached after 9-10 days which reflects the qualitative composition of the diet with crayfish powder. The remaining pigments (lutein, zeaxanthin and canthaxanthin) showed a slight decrease in their concentration values, which after 9-10 days were stable with time (ca. $19 \mathrm{mg} / \mathrm{kg}, 21 \mathrm{mg} / \mathrm{kg}$ and 5.5 $\mathrm{mg} / \mathrm{kg}$ for lutein, zeaxanthin and canthaxanthin, respectively). Considering the total amount of pigments, it was observed that increased in a similar trend to that of astaxanthin reaching ca. 66 $\mathrm{mg} / \mathrm{kg}$ at the end of the experiment, that is, a stable value which was reached and maintained after 9-10 days of introducing the crayfish powder into the diet.

Taking into account the data corresponding to all the hens and getting mean values at each time point for each variable (concentration of astaxanthin, lutein, zeaxanthin, canthaxanthin and total pigments) the trend was similar to the before mentioned. In order to give a clear picture of the evolution of the 
Table 2

Evolution of the carotenoid profile of egg yolk corresponding to one of the laying hens during the feeding period with crayfish powder added to the diet (20\%). Data are expressed in $\mathrm{mg}$ of pigment per $\mathrm{kg}$ of egg yolk

\begin{tabular}{cccccc}
\hline Time $(\mathbf{d})$ & Astaxanthin & Lutein & Zeaxanthin & Canthaxanthin & Total \\
\hline $0^{1}$ & 0.000 & 21.412 & 24.265 & 7.770 & 53.446 \\
1 & 0.000 & 21.813 & 23.514 & 7.940 & 53.267 \\
2 & 0.623 & 20.462 & 21.477 & 8.207 & 50.768 \\
3 & 3.203 & 19.111 & 19.193 & 7.117 & 48.624 \\
4 & 8.191 & 19.754 & 20.389 & 7.550 & 55.884 \\
5 & 15.226 & 18.384 & 15.245 & 6.428 & 55.283 \\
6 & 15.545 & 18.302 & 17.780 & 6.741 & 58.367 \\
7 & 20.113 & 18.663 & 15.759 & 6.131 & 60.666 \\
8 & 20.591 & 19.358 & 15.386 & 5.792 & 61.127 \\
9 & 22.240 & 20.963 & 17.287 & 5.764 & 66.254 \\
10 & 22.055 & 19.307 & 19.957 & 5.867 & 67.186 \\
11 & 19.346 & 18.562 & 20.783 & 6.063 & 64.753 \\
13 & 21.012 & 18.429 & 22.191 & 6.300 & 67.932 \\
\end{tabular}

${ }^{1}$ Reference values before including the crayfish powder in the diet. One egg was laid per day.

pigment profile, Figure 2 shows the time evolution of the carotenoids provided with the mixed diet with astaxanthin, lutein, zeaxanthin and canthaxanthin. With respect to the reference values of carotenoid concentrations (at time 0), astaxanthin was clearly detected in the chromatograms after 48-72 $\mathrm{h}$ (samples 2-3) showing that the deposit of carotenoids in eggs is a rapid process in agreement with previous results (Marusich and Bauernfiend, 1981). In addition, astaxanthin was absorbed and transferred without modifications of its structure. However, the increase in astaxanthin concentration was only significant after fours days of including the crayfish powder in the diet where the mean value of concentration was $4.84 \mathrm{mg} / \mathrm{kg}$. . Astaxanthin levels in egg yolk reached a plateau period between samples 9-10 with an amount in the range of 13-14 $\mathrm{mg} / \mathrm{kg}$, which stayed more or less constant during the rest of the experiment. Data showed that astaxanthin from crayfish powder is absorbed and transferred to the egg yolk and incorporated into the carotenoid profile of the yolk, increasing its coloring capacity with noticeable results after only 3 days of supplemented diet.

In the case of lutein, a decrease in the concentration was observed but this was not statistically significant. The concentration of zeaxanthin also decreased and in this case the decrease was significant after five days with the new diet. The mean value reached at that time $(13.88 \mathrm{mg} / \mathrm{kg}$ ) remained constant afterwards so the zeaxanthin concentration was readjusted over five days obtaining a balanced value that was constant until the end of the experiment. In the case of canthaxanthin, a decrease in the concentration was noted but this was only significant after five days of introducing the crayfish powder into the diet reaching a mean value of $6.22 \mathrm{mg} / \mathrm{kg}$. Unlike the case of zeaxanthin, this value was not constant and canthaxanthin concentration continued to decrease until the end of the experiment, obtaining values that were significantly lower and reaching a minimum value of $4.81 \mathrm{mg} / \mathrm{kg}$. For canthaxanthin, the introduction of crayfish powder into the hens' diet supposed a permanent correction in its participation in the carotenoid profile with a trend towards reduction. It must be noted that these changes ( 5 days decreasing period for zeaxanthin, and the continuous fall in the concentration of canthaxanthin) were compensated by the introduction of astaxanthin so the total pigment concentration showed no differences, neither increases nor decreases, in the whole experiment.

It was observed that the introduction of crayfish powder in the feeding of laying hens substantially modified the pigment profile of the egg yolk qualitatively, but also the incorporation of astaxanthin affected the quantitative absorption of some of the carotenoids initially present in the diet. For lutein and zeaxanthin, a regulation period was detected that only significantly affected zeaxanthin. This initial period could be considered as an adaptation to the change of composition of the diet and the decrease observed for zeaxanthin corresponds to the dilution factor of the initial diet $(20 \%)$, that is, a reduction in the dosage of zeaxanthin is reproduced in the composition of egg yolk in a similar fashion. The concentration of lutein in egg yolk did not reproduce the dilution level (20\%) according to dosage and the concentration levels were kept constant. In this case it must be considered that the assimilation of lutein is predominant and the decrease in dosage could be compensated by an active transport mechanism of absorption for this pigment. That period of five days corresponds to a stage of continuous increase in the deposit rate of astaxanthin in the egg yolk. This deposit rate can be observed in Figure 3. The curve has been obtained by differentiation of the data corresponding to the astaxanthin concentration in 

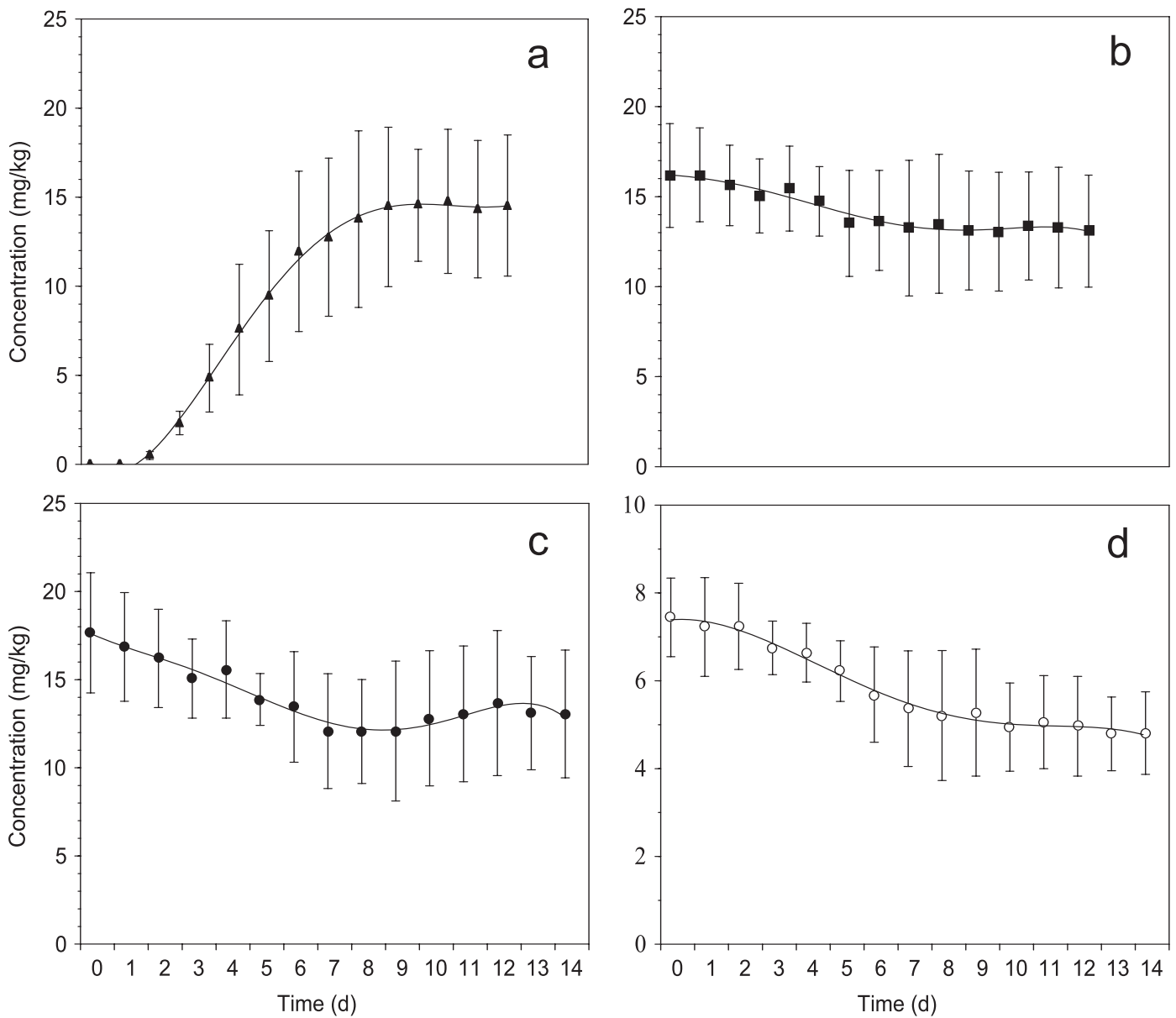

Figure 2

Evolution of the carotenoids analyzed in egg yolk extracts during the supplementation study using a $20 \%$ crayfish powder. Data are presented as mean \pm SEM corresponding to the evolution of astaxanthin (a), lutein (b), zeaxanthin (c), canthaxanthin (d).

egg yolk vs. time (see Figure 2a). The deposition rate data are fitted to a third order polynomial equation. This figure clearly shows that astaxanthin is accumulated in egg yolk during the five days at increased rates, a stage which fits with the correction period of the concentrations of lutein

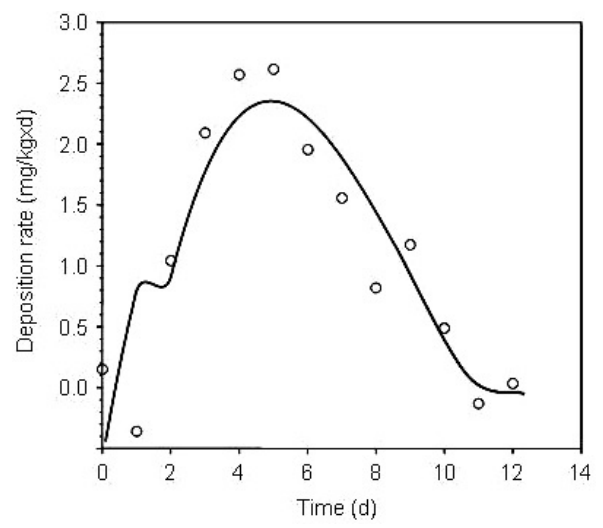

Figure 3

Deposit rate of astaxanthin in egg yolk (expressed as $\mathrm{mg} / \mathrm{kg} \times \mathrm{d}$ ) as a function of time with the supplemented diet with crayfish powder. (although this was not significant) and zeaxanthin. Astaxanthin incorporation only altered, continuously and significantly, the absorption of canthaxanthin. Both pigments are structurally similar and a competition for absorption could be established. This kind of interaction has been reported previously and the selective uptake could be based on several factors (competition for uptake in mixed micelles and/or uptake in chylomicrons, even inhibition in tissue uptake). Some animal models report this kind of interaction (Bierer et al., 1995; Clark et al., 1998).

Considering the quantitative composition of the diet, with astaxanthin as the main pigment $(56 \%$ of total carotenoids) this dosage is not reproduced in the egg yolk pigment quantitative composition. Figure 4 shows the percentage composition of the egg yolk at the beginning and end of the experiment, including the composition of the diet, both initially and once supplemented with crayfish powder. Although astaxanthin was the main pigment, this carotenoid is not accumulated in the egg yolk according to the dosage levels at which it was supplemented. The efficiency of incorporation of each carotenoid was calculated from data on carotenoid content in diets (either normal or 


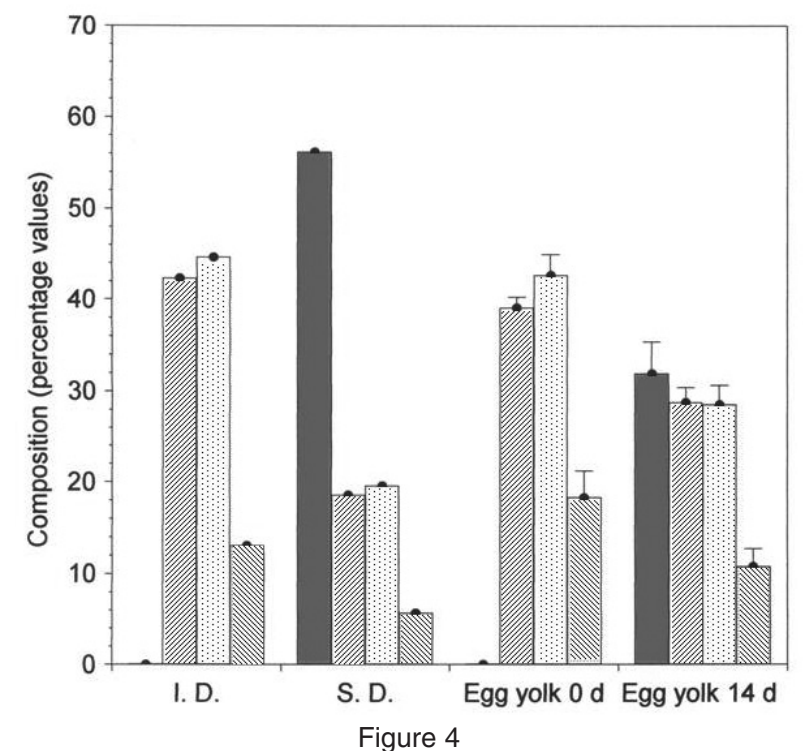

Modification of the carotenoid profile (composition expressed in percentage) corresponding to the initial diet (I. D.) supplemented diet (S. D.) and egg yolk extracts at $t=0 \mathrm{~d}$ and $t=14$ of the supplementation study using a $20 \%$ crayfish powder. Data are presented as mean \pm SEM corresponding to astaxanthin (bold bar), canthaxanthin (diagonal-down bar), lutein (diagonal-up bar) and zeaxanthin (dotted bar).

supplemented diet) and data on carotenoid content in egg yolk. Thus, astaxanthin incorporation in egg yolk reached an efficiency of only $14 \%$ from the supplemented diet. It must be pointed out that the absorption of astaxanthin is hindered by the matrix composition of the crayfish powder, which presents a very complex and compact structure. The bioaccessibility of astaxanthin from this kind of matrix is lower in comparison with other food matrixes, even in the original feeding that crayfish powder was mixed with. However, this drawback in bioaccessibility did not affect the goal of this study which was to increase the color of egg yolk through the introduction of crayfish powder (containing astaxanthin). The amount of astaxanthin accumulated in the egg yolk was sufficient to substantially increase the coloration of egg yolk. Table 3 shows the evolution of the egg yolk color evaluated by means of the Roche Yolk Color Fan. The color of egg yolks after 9 days of experiment reached values out of scale (higher than 15). The carotenoid astaxanthin provides an intensified effect on lutein and zeaxanthin coloration without any pink color because the diet supplied a mixture of red and yellow pigments. An optimal proportion is also established because it is known that too much astaxanthin produces pinkish yolks, what was not observed in this study (Nelson and Baptist, 1968). Crayfish powder could be used as a complementary natural source as feed pigmenter to reinforce the coloring effect of yellow carotenoids found in normal diets, so residues from the crayfish industry could then be considered as a by-product that could be used to for this purpose, therefore replacing synthetic carotenoids.

\section{CONCLUSION}

It is possible to obtain a deep red coloration of the egg yolk obtained through the introduction of crayfish powder, as a source of carotenoid astaxanthin, in the feed of laying hens. The bioaccessibility of astaxanthin from crayfish powder is enough to increase the red hue of the yolk, only affecting the canthaxanthin accumulation but not that of lutein or zeaxanthin. The artificial supplementation of the feed with canthaxanthin could be substituted by the crayfish powder which is a product of plant processing waste.

Final note: Once the study was finished, the hens were released to a traditional farm were they received a diet free of artificial pigments. During some time the coloration of the egg yolk continued with a higher red hue in comparison with the color of egg yolks laid by other hens.

Table 3

Evolution of the egg yolk color evaluated with the Roche color Fan during the feeding period supplemented with $20 \%$ crayfish powder

\begin{tabular}{|c|c|c|c|c|c|c|c|c|c|c|c|c|c|c|c|c|}
\hline \multirow{2}{*}{$\begin{array}{c}\text { Time } \\
\text { (d) }\end{array}$} & \multicolumn{16}{|c|}{ Laying hen number } \\
\hline & 1 & 2 & 3 & 4 & 5 & 6 & $\begin{array}{l}7 \\
\text { Egs }\end{array}$ & $\begin{array}{c}8 \\
\text { olk }\end{array}$ & $\begin{array}{c}9 \\
\text { or } \mathbf{v}\end{array}$ & $\begin{array}{c}10 \\
\text { ies }\end{array}$ & 11 & 12 & 13 & 14 & 15 & 16 \\
\hline 0 & 13 & 12 & 13 & 13 & 13 & 13 & 13 & 13 & 12 & 13 & 14 & 12 & 13 & 14 & 13 & 13 \\
\hline 1 & 13 & 12 & 13 & 13 & 13 & 13 & 13 & 14 & 13 & 13 & 14 & 12 & 14 & 14 & 13 & 13 \\
\hline 2 & 13 & 13 & 14 & 14 & 13 & 14 & 14 & 14 & 14 & 13 & 15 & 13 & 15 & 14 & 14 & 14 \\
\hline 3 & 14 & 13 & 14 & 14 & 14 & 14 & 15 & 15 & 14 & 14 & -1 & 13 & 15 & 15 & 15 & 14 \\
\hline 4 & 15 & 13 & 15 & 14 & 15 & 15 & 15 & 15 & 15 & 14 & - & 14 & - & 15 & - & 14 \\
\hline 5 & 15 & 14 & - & 15 & 15 & 15 & - & 15 & - & 15 & - & 14 & - & - & - & 15 \\
\hline 6 & 15 & 14 & - & 15 & 15 & 15 & - & - & - & 15 & - & 15 & - & - & - & 15 \\
\hline 7 & - & 15 & - & 15 & 15 & - & - & - & - & - & - & 15 & - & - & - & 15 \\
\hline 8 & - & 15 & - & - & - & - & - & - & - & - & - & 15 & - & - & - & - \\
\hline $9^{2}$ & - & - & - & - & - & - & - & - & - & - & - & - & - & - & - & - \\
\hline
\end{tabular}

\footnotetext{
${ }^{1}$ Value higher than 15 , and out of the scale. ${ }^{2}$ All eggs laid from day nine of the experiment showed a value higher than 15 , exceeding
} the maximum rank of the Roche Fan. 


\section{ACKNOWLEDGEMENTS}

The authors express their sincere gratitude to Francisco García for his technical assistance during the development of this experiment.

\section{REFERENCES}

Bierer TL, Merchen NR, Erdman JW. 1995. Comparative absorption and transport of five common carotenoids in preruminant calves. Journal of Nutrition 125, $1569-1577$.

Blanch A. 1999. Use of yellow carotenoids for yolk pigmentation. International Poultry Production 7, 23-25.

Bortolotti GR, Negro JJ, Tella JL, Tracy AM, Bird DB. 1996. Sexual dichromatism in birds independent of diet, parasites and androgens. Proceedings of the Royal Society of London B 263, 1171-1176.

Carranco ME, Calvo C, Arellano L. 2003. Inclusión de la harina de cabezas de camarón penaeus sp. en raciones para gallinas ponedoras. Efecto sobre la concentración de pigmento rojo de yema y calidad de huevo. INCI 28, 328-333.

Chen HM, Meyers SP. 1982. Extraction of astaxanthin pigment from crawfish waste using a soy oil process. Journal of Food Science 47, 892-900.

Chen HM, Meyers SP. 1984. A rapid quantitative method for determination of astaxanthin pigment concentration in oil extracts. JAOCS 61, 1045-1047

Clark RM, Yao L, She L, Furr HC. 1998. A comparison of lycopene and canthaxanthin absorption: using the rat to study the absorption of non-provitamin A carotenoids. Lipids 33, 159-163.

Delgado-Vargas F, Paredes-López O, Avila-González E. 1998. Effects of sunlight illumination of marigold flowers meals on egg yolk pigmentation. Journal of Agricultural and Food Chemistry 46, 698-706.

European Commission. 1986. On the protection of animals used for experimental and other scientific purposes. Directive 86/609/EEC.

Goodwin TW. 1984. The biochemistry of the carotenoids, volumen 2 Animals, Chapman and Hall, New York, NY.
Hamilton PB, Tirado FJ, García-Fernández F. 1990. Deposition in egg yolk of the carotenoids from saponified and unsaponified oleoresin of red peper (Capsicum annuum) feed to laying eggs. Poultry Science 69, 462-470.

Karunajeewa H, Hughes RJ, McDonald MW, Shenstone FS. 1984. A review of factors influencing pigmentation of egg yolks. World's Poultry Science Journal 40, 52-65.

Marusich WL, Bauernfiend JC. 1981. Oxycarotenoids in poultry feeds, en Bauernfiend JC. (Ed.) Carotenoids as Colorants and Vitamin A Precursors. Academic Press, New York.

Meyers SP, Bligh D. 1981. Characterization of astaxanthin fron heat-processe crayfish waste. Journal of Agricultural and Food Chemistry 29, 505-508

Mínguez-Mosquera MI. 1997. Clorofilas y Carotenoides en Tecnología de Alimentos. Secretariado de Publicaciones de la Universidad de Sevilla. Sevilla.

Negro JJ, Tella JL, Forero MG, Garrido-Fernández J. 2000. Diet explains interpopulation of plasma carotenoids and skin pigmentation in nestling white storks. Physiological and Biochemical Zoology 73 , 97-101.

Nelson TS, Baptist JN. 1968. Feed pigments. 2. The influence of feeding single and combined sources of red and yellow pigments on egg yolk colour. Poultry Science 47, 924-931.

Nys Y. 2000. Dietary carotenoids and egg yolk colorationA review. Archiv fuer Gefluegelkunde 64, 45-54.

Royle NJ, Surai PF, McCartney RJ, Speake BK. 1999. Parental investment and egg yolk lipid composition in gulls. Functional Ecology 13, 298-306.

Santos-Bocanegra E, Ospina-Osorio X, Oviedo-Rondón EO. 2004. Evaluation of xanthophylls from tageters erectus (Marigold-flower) and Capsicum sp (red pepper paprika) as a pigment for egg-yolks compare with synthetic pigments. International Journal of Poultry Science 3, 685-689.

Surai PF, Speake BK. 1998. Distribution of carotenoids from the yolk to the tissues of the chic embryo. Journal of Nutritional Biochemistry 9, 645-651.

Recibido: 16/10/07 Aceptado: 27/11/07 